\title{
Corrigendum
}

\section{Corrigendum to “A Lip Lump: An Unexpected Histological Diagnosis of a Lip Schwannoma"}

\author{
Thomas Haigh (D), ${ }^{1}$ Raad John Glore, ${ }^{1}$ David Gouldesbrough, ${ }^{1}$ and Winson Wong ${ }^{2}$ \\ ${ }^{1}$ Bradford Teaching Hospitals NHS Foundation Trust, Bradford BD9 6RJ, UK \\ ${ }^{2}$ Bradford Teaching Hospitals NHS Foundation Trust, University of Leeds, Leeds, UK \\ Correspondence should be addressed to Thomas Haigh; t_haigh@hotmail.co.uk \\ Received 3 July 2019; Accepted 9 July 2019; Published 21 July 2019 \\ Copyright $(92019$ Thomas Haigh et al. This is an open access article distributed under the Creative Commons Attribution License, \\ which permits unrestricted use, distribution, and reproduction in any medium, provided the original work is properly cited.
}

In the article titled "A Lip Lump: An Unexpected Histological Diagnosis of a Lip Schwannoma” [1], the name of the second author was given incorrectly as John Raad Glore. The author's name should have been written as Raad John Glore. The revised authors' list is shown above.

\section{References}

[1] T. Haigh, J. R. Glore, D. Gouldesbrough, and W. Wong, “A lip lump: an unexpected histological diagnosis of a lip schwannoma," Case Reports in Otolaryngology, vol. 2017, Article ID 3107362, 2 pages, 2017. 


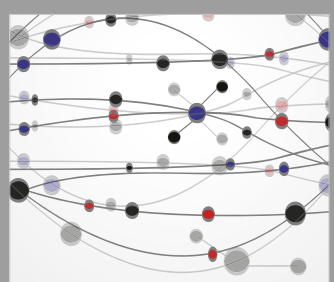

The Scientific World Journal
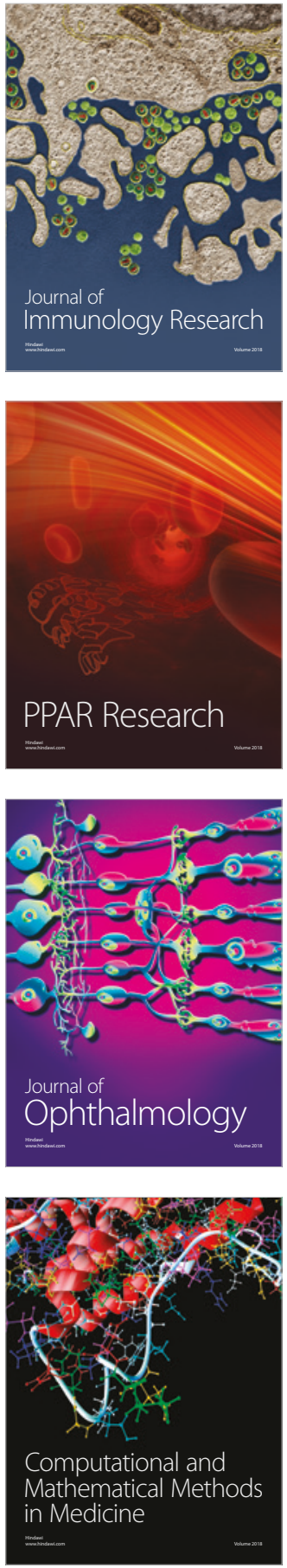

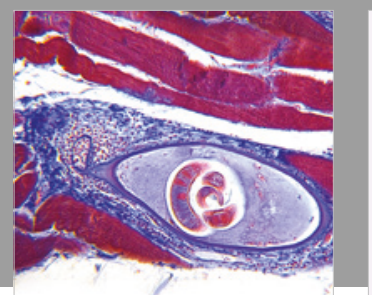

Gastroenterology Research and Practice

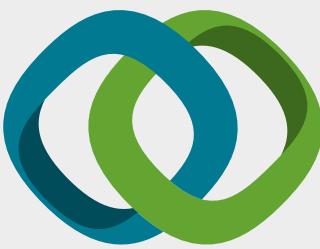

\section{Hindawi}

Submit your manuscripts at

www.hindawi.com
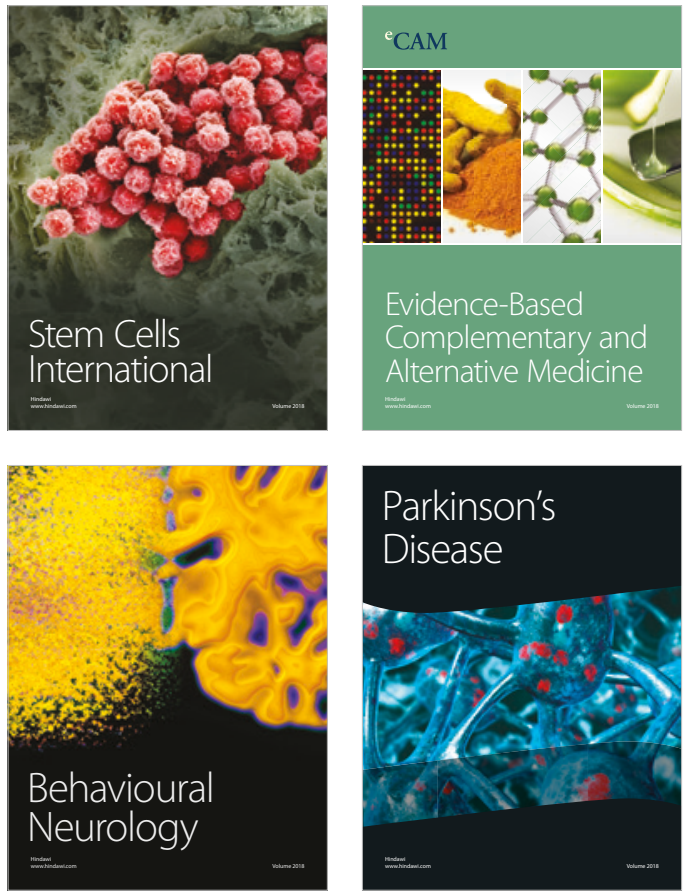

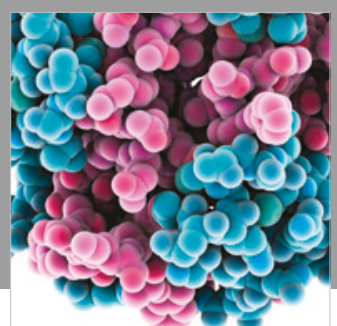

ournal of

Diabetes Research

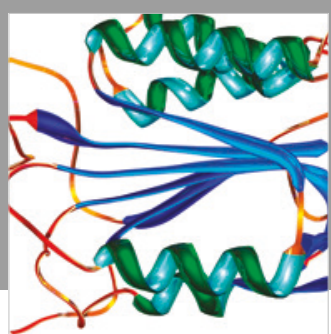

Disease Markers
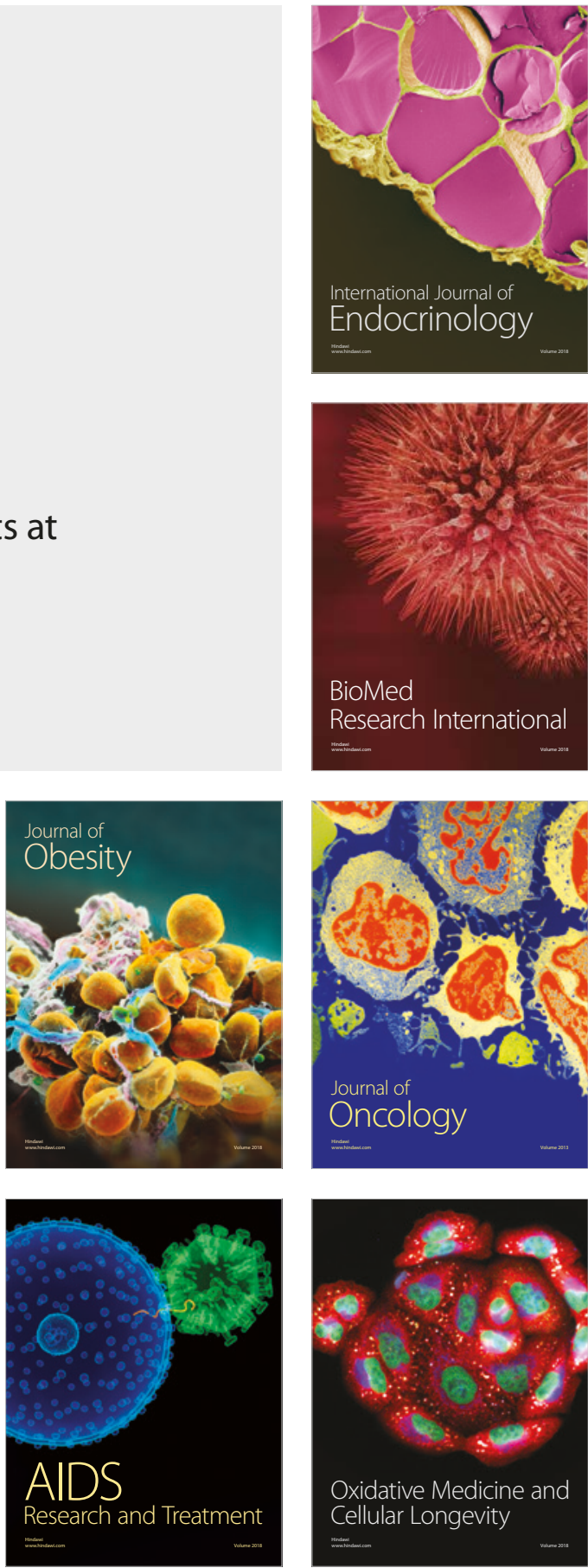